\title{
From Early Family Systems to Internalizing Symptoms : The Role of Emotion Regulation and Peer Relations
}

\section{Lindblom, Jallu}

2017-04

Lindblom , J , Vänskä, M , Flykt , M , Tolvanen , A , Tiitinen , A , Tulppala , M \& Punamäki , R-L 2017 , ' From Early Family Systems to Internalizing Symptoms : The Role of Emotion Regulation and Peer Relations ' , Journal of Family Psychology , vol. 31 , no. 3 , pp. 316-326 . https://doi.org/10.1037/fam0000260

http://hdl.handle.net/10138/228738

https://doi.org/10.1037/fam0000260

acceptedVersion

Downloaded from Helda, University of Helsinki institutional repository.

This is an electronic reprint of the original article.

This reprint may differ from the original in pagination and typographic detail.

Please cite the original version. 
Running head: PATHWAYS FROM EARLY FAMILY TYPES TO INTERNALIZING

This is author manuscript.

This article may not exactly replicate the authoritative document published in the APA journal. It is not the copy of record.

From Early Family Systems to Internalizing Symptoms:

the Role of Emotion Regulation and Peer Relations

Authors: Jallu Lindblom, Mervi Vänskä, Marjo Flykt, Asko Tolvanen, Aila Tiitinen, Maija Tulppala, Raija-Leena Punamäki

Journal of Family Psychology 2016 Nov 17 [epub ahead of print]

DOI: http://doi.org/10.1037/fam0000260 
Running head: PATHWAYS FROM EARLY FAMILY TYPES TO INTERNALIZING

\begin{abstract}
Research has demonstrated the importance of early family characteristics, such as the quality of caregiving, on children's later mental health. Information is, however, needed about the role of more holistic family systems and specific child-related socioemotional mechanisms. In this study, we conceptualize families as dynamic family system types, consisting of both marital and parenting trajectories over the transition to parenthood. First, we examine how early family system types predict children's anxiety, depression, peer exclusion and emotion regulation. Second, we test whether couple's infertility history and other family-related contextual factors moderate the effects of family system types on child outcomes. Third, we test whether children's emotion regulation and peer exclusion mediate the effects of family system types on anxiety and depression. The participants were 452 families representing cohesive, distant, authoritative, enmeshed, and discrepant family types, identified on the basis of relationship autonomy and intimacy from pregnancy to the child's age of 2 and 12 months. Children's anxiety, depression, emotion regulation, and peer exclusion were assessed at the age of 7-8 years. Structural equation modeling showed that distant, enmeshed, and discrepant families similarly predicted children's heightened anxiety and depression. Infertility history, parental education, and parity moderated the associations between certain family system types and child outcomes. Finally, emotion regulation, but not peer exclusion, was a common mediating mechanism between distant and enmeshed families and children's depression. The results emphasize the importance of early family environments on children's emotion regulation development and internalizing psychopathology.
\end{abstract}

Keywords: anxiety; depression; emotion regulation; emotional problems; family relationships; infancy; infertility; peer exclusion; trajectories; transition to parenthood 
Running head: PATHWAYS FROM EARLY FAMILY TYPES TO INTERNALIZING

Child development fundamentally takes place within family relationships. Both parentchild and interparental interactions shape how children express and regulate their emotions (Morris, Silk, Steinberg, Myers, \& Robinson, 2007) and relate to self and others (Davies \& Martin, 2013). Early developmental alterations in these socioemotional processes can heighten the risk for emotional problems in later life (Brumariu \& Kerns, 2010). Indeed, there is some evidence about the mediating role of emotion regulation and peer relationships between early family experiences and children's later internalizing symptoms (e.g., Kim \& Cicchetti, 2010). Further, families interact with a number of contextual factors. In the current study, half of the participating couples had infertility history. Involuntary infertility can influence both family dynamics and children's vulnerability to family dysfunctions (Barnes et al., 2004). However, it is not yet well understood how family system types and contextual factors shape children's socioemotional processes and specific internalizing disorders. In this study, we conceptualize family system types as parental and marital trajectories from pregnancy to child's infancy. We model how these complex family system types, together with former infertility and other contextual factors, predict children's anxiety and depression in middle childhood. Furthermore, we test the mediating role of children's emotion regulation and peer exclusion between early family system types and child anxiety and depression.

\section{Families and Children's Internalizing Symptoms}

Anxiety and depression are often considered together as internalizing symptoms due to their phenomenological similarities. Evolutionary models of psychopathology suggest, however, that anxiety and depression have evolved to serve different adaptive functions (Stevens \& Price, 2000). For example, anxiety may foster coping with threats and dangers, and depression with interpersonal conflicts and losses (Eley \& Stevenson, 2000; Sloman, Farvolden, Gilbert, \& Price, 2006). Emotional security theory extends evolutionary perspective to family context, and suggests that children may develop anxiety and worry to 
Running head: PATHWAYS FROM EARLY FAMILY TYPES TO INTERNALIZING

ensure parental protection in enmeshed families, and depression and withdrawal to avoid conflicts in distant families (Davies \& Martin, 2013). In line with this, a meta-analysis of parenting, based mostly on cross-sectional studies, provided some evidence that enmeshed parenting (e.g., parental overprotection and lack of autonomy support) would predict child anxiety (McLeod, Wood, \& Weisz, 2007), whereas distant parenting (e.g., parental hostility and rejection) would predict child depression (McLeod, Weisz, \& Wood, 2007). However, a more recent meta-analysis of parenting, based on longitudinal studies, found only weak evidence of symptom-specificity (Yap \& Jorm, 2015). One explanation for the lack of symptom-specificity could be that children develop anxiety and depression as a response to more complex family patterns, involving both the parenting and the marital relationships.

According to emotion regulation models of psychopathology, dysfunctional family relationships are detrimental because they disturb children's ability to modulate their emotional experiences and responses (Morris et al., 2007; Suveg, Morelen, Brewer, \& Thomassin, 2010). Family conflicts, as well as overly strict, intrusive or distant caregiving, decrease children's sense of safety and limit experiences of emotional scaffolding, both essential for the development of emotion regulation (Davies \& Martin, 2013; Thompson \& Meyer, 2007). Intriguingly, inefficient regulation of negative emotions could heighten children's general risk for internalizing symptoms, and thus explain the lack of symptomspecificity (i.e., developmental equifinality) in previous family studies. In line with this, some studies have found inefficient emotion regulation to mediate the effects of child maltreatment on internalizing symptoms in middle childhood (e.g., Kim \& Cicchetti, 2010), as well as on depression in adulthood (Abravanel \& Sinha, 2015). Yet, studies in the context of more normative family relationships are scarce: In one retrospective study, Suveg et al. (2010) found inefficient emotion regulation to mediate the effects of emotionally distant and conflictual families on anxiety among young adults. 
Running head: PATHWAYS FROM EARLY FAMILY TYPES TO INTERNALIZING

Peer relationships become increasingly important in middle childhood. Thus, it is not surprising that peer victimization and exclusion predict heightened internalizing symptoms among 7- to 12-year-olds (Reijntjes, Kamphuis, Prinzie, \& Telch, 2010). Emotional security theory suggests that harmonious families foster children's internal security and social skills, both needed to form and maintain mutually beneficial peer relationships (Davies \& Martin, 2013). In line with this, there is robust evidence from attachment research that early parentchild attachment security predicts children's competence with peers (Groh et al., 2014). Thus, peer exclusion is a potential linking mechanism between early family relationships and later internalizing symptoms. Because peer relationships and emotion regulation are developmentally interrelated (e.g., Kim \& Cicchetti, 2010), it is important to consider them together when examining their unique mediating roles on internalizing symptoms.

\section{Former Infertility and Other Family-Related Contextual Factors}

Family relations are affected by various contextual factors, which together shape child development (Lucas-Thompson \& Goldberg, 2011). Contextual factors can increase children's vulnerability to mental health problems or provide protection against them. Half of the couples participating in the current study had experienced involuntary infertility. Infertility is considered an emotionally burdening life challenge, and the assisted reproductive treatments (ART) can last years before pregnancy is achieved (Barnes et al., 2004). However, most studies suggest that ART parents have similar marital and parenting quality compared to naturally conceiving (NC) parents (Wilson, Fisher, Hammarberg, Amor, \& Halliday, 2011), and some studies suggest even higher resilience in parenting among ART families (Repokari et al., 2006). Yet, there is some indication that ART parents experience difficulties in coordinating triadic family interactions (Cairo et al., 2012) and tend to be overly protective of their children (Barnes et al., 2004). ART children also have somewhat heightened risk for internalizing symptoms, perhaps due to family dynamic (e.g., enmeshment) and infertility- or 
Running head: PATHWAYS FROM EARLY FAMILY TYPES TO INTERNALIZING

treatment-related biological factors (Barnes et al., 2004; Wilson et al., 2011). However, previous studies have not examined the combined effects of early family relationships and former infertility on children's later mental health.

Due to the nature of infertility, ART parents are more often primiparous. Primi- as compared to multiparous parents tend to experience higher marital satisfaction (Twenge, Campbell, \& Foster, 2003) and stronger parent-child attachment (Lorensen, Wilson, \& White, 2004) during the transition to parenthood. Furthermore, high parental education level has been shown to decrease marital satisfaction (Twenge et al., 2003), but also to increase parenting sensitivity (Tamis-LeMonda, Shannon, Cabrera, \& Lamb, 2004). Interestingly, Buehler et al. (1997) found in their meta-analysis that high parental education level protected adolescent's mental health against marital conflicts, whereas McLeod, Weisz et al. (2007) found high parental education level to be a vulnerability factor for adolescent's depression when facing parenting problems. Considering the ambiguous findings of previous research, it seems possible that former infertility, parity, and parental education level may act as either protective or vulnerability factors, depending on the relational quality of the family.

\section{Families as Complex and Dynamic Systems}

Family systems theory conceptualizes families as dynamic systems in which all dyadic relationships and the marital and parenting subsystems influence each other (Cox \& Paley, 2003). For example, interparental conflicts and power asymmetries tend to disturb family boundaries, increase negative spillover from marital to parenting subsystem and thus increase the risk for child psychopathology (e.g., Lindahl, Malimk, Kaczynski, \& Simons, 2004). Such complex interactions between subsystems constitute the holistic and dynamic family system. A person-oriented approach is well suited for holistic family research as it enables identifying family types based simultaneously on multiple family relationships and their dynamics over time (Bergman \& Magnusson, 1997). Furthermore, it opens up an opportunity to examine 
Running head: PATHWAYS FROM EARLY FAMILY TYPES TO INTERNALIZING

how the naturally occurring family environments influence developmental psychopathology.

However, only few person-oriented studies have focused on early family systems and children's mental health. For example, Sturge-Apple et al. (2014) identified three family types based on family patterns of interparental conflict and parenting when the children were two years old: adequate families were characterized by low levels of interparental conflicts and average parenting quality, spillover families by severe interparental conflicts and highly insensitive parenting, and compartmentalizing families by high levels of interparental conflicts coupled with sensitive parenting. Interestingly, children from spillover families showed decreased cortisol levels and increased anxiety and depression at the age of 3 years, demonstrating the detrimental effects of overly permeable family boundaries on children's psychophysiological stress regulation and mental health. Favez et al. (2012) identified three family types based on longitudinal changes in family interactions during the transition to parenthood: two types of stable families were characterized by either low or high overall interaction quality, and deteriorating families were characterized by decreasing interaction quality from pregnancy to the postnatal period. At the age of 5 years, children from stable families with low interaction quality showed poor social understanding and children from deteriorating families showed increased mental health problems.

Despite the progress in person-oriented family research, studies modeling both multiple family relationships and their longitudinal changes are lacking. To fill this research gap, in our previous study, we used factor mixture modeling to identify family system types as multidimensional relationship trajectories from pregnancy to the child's ages of 2 and 12 months (ref_blinded, xxxx). In that study, 710 mothers and fathers reported relational autonomy and intimacy in the marital subsystem, i.e., mother-to-father and father-to-mother, and in the parenting subsystem, i.e., mother-to-child and father-to-child, at each of the three assessments (i.e., 48 variables). Autonomy refers to the degree of relational self-assurance 
Running head: PATHWAYS FROM EARLY FAMILY TYPES TO INTERNALIZING

and independence, and intimacy to the degree of emotional closeness and acceptance (Mattejat \& Scholz, 1994), reflecting together the two most basic psychological needs expressed in family relationships (Luyten \& Blatt, 2011). During pregnancy, parents reported their expectations of the future relationships with the unborn child, which have been shown to predict and guide the actual postnatal parent-child interactions (Harwood, Neil, \& Kevin, 2007). The assessment of both parents' perceptions of the same family relationships allowed us to identify parental discrepancies that have been found to predict developmental problems, such as academic underachievement and aggression at the school age (Johnson, 2005).

The identified family system types differed in overall levels of autonomy and intimacy, in longitudinal dynamics, relationship patterns, as well as in parental discrepancies. The current study focuses on five family system types, shown in Figure 1: Cohesive families (39\%) had the highest levels of both emotional intimacy and autonomy. Family autonomy increased slightly from pregnancy to the child's age of 12 months. Such dynamics indicate harmonious and egalitarian family relationships. Authoritarian families (16\%) showed a relative lack of intimacy combined with average levels of autonomy. Family intimacy declined only slightly from pregnancy to the age of 12 months. Such dynamics indicate strong family boundaries and resistance against change. Discrepant families (16\%) were the only family system type in which parents differed in their perceptions of family relationships. Fathers perceived less family autonomy and intimacy than mothers, whereas both parents perceived a decline in intimacy from 2 to 12 months. Such dynamics indicate highly different transitional processes between the parents. Enmeshed families (12\%) had low levels of autonomy combined with moderately high levels of intimacy. Family intimacy declined from 2 to 12 months. Such dynamics indicate permeable family boundaries and enmeshed family relationships. Distant families (10\%) had the lowest levels of both emotional intimacy and autonomy. Family intimacy declined from pregnancy to the age of 12 months. Such dynamics 
Running head: PATHWAYS FROM EARLY FAMILY TYPES TO INTERNALIZING

indicate emotionally distant and conflictual family relationships. Our original analysis identified seven family system types, but in this study we grouped two small enmeshed families (both lacking autonomy but not intimacy) and two highly distant families (both lacking autonomy and intimacy at 12 months) to enmeshed and distant families, respectively. For statistical justification of the grouping, see the structural invariance tests in Results.

\section{[ Insert Figure 1 about here ]}

\section{The Current Study}

The aim of the study is to model how the early family system types, contextual factors and socioemotional processes together shape children's anxiety and depression. As shown in Figure 2, we model how early family system types (cohesive, authoritarian, discrepant, enmeshed and distant) predict children's anxiety, depression, emotion regulation and peer exclusion at the age of 7-8 years. We use cohesive families as a reference group because it represents the most harmonious and the most common group of families.

\section{[ Insert Figure 2 about here ]}

First, we examine how early family system types directly predict children's depression, anxiety, emotion regulation and peer exclusion ( $a_{1}$ and $a_{2}$-paths in Figure 2). According to our specificity hypothesis, derived from evolutionary models of psychopathology, we expect family system types to differentially predict anxiety and depression. More precisely, we expect enmeshed families to predict children's heightened anxiety, and distant families to predict children's heightened depression.

Second, we test how former infertility and other family-related contextual factors moderate the effects of early family system types on anxiety, depression, emotion regulation and peer exclusion (b-paths in Figure 2). According to our contextual factors hypothesis, we expect former infertility, parity and parental education level to either protect or heighten vulnerability for internalizing symptoms and socioemotional problems depending on the 
Running head: PATHWAYS FROM EARLY FAMILY TYPES TO INTERNALIZING

family system type. Additionally, we test the moderating role of child's gender. Due to previous ambiguous findings, we do not pose family system type -specific hypotheses.

Third, we test whether children's emotion regulation and peer exclusion mediate the effects of early family system types on depression and anxiety ( $\mathrm{a}_{1}$ and c-paths in Figure 2 ). According to our emotion regulation hypothesis, derived from emotion regulation models of psychopathology, we expect emotion regulation to account for the associations between family system types and anxiety and depression. As a parallel mediating process, we also expect peer exclusion to mediate between family system types and anxiety and depression.

\section{Methods}

\section{Participants}

The participants were married or cohabiting Finnish Caucasian couples $(N=710)$. In our previous study, we used the same sample to identify different family system types (ref_blinded, xxxx). In the previous study, couples completed questionnaires about family relationships during pregnancy (T1; 18-20 weeks of gestation), and when the child was 2 months (T2) and 12 months old (T3). Response rates ranged from $71 \%$ to $89 \%$ for fathers, and from $77 \%$ to $95 \%$ for mothers. Approximately half of the couples had conceived naturally (NC; $n=374,53 \%)$; the other half had achieved pregnancy after assisted reproductive treatment (ART; $n=336,47 \%$ ). Participants were recruited from infertility clinics and while attending routine ultrasonographic examinations. Couples with multiple pregnancies were excluded from the study sample and only women above the age of 25 years were included in the NC-group. The recruited mothers $(M=33.21$ years, $S D=3.71)$ were older than the Finnish national average of mothers giving birth $(M=29.9$ years $)$ and had higher education levels than the corresponding population (Statistics Finland, 2013). For a more detailed description of the larger longitudinal sample, see ref_blinded (xxxx).

At the child's age of 7-8 years (T4) both mothers and fathers were contacted and asked 
Running head: PATHWAYS FROM EARLY FAMILY TYPES TO INTERNALIZING

to fill in child-related questionnaires. Response rate at T4 was $69 \%(n=491)$ for at least one parent participating, 68\% $(\mathrm{n}=485)$ for mothers, and $42 \%(\mathrm{n}=299)$ for fathers. Attrition at T4 was independent of the early family system type, former infertility, child's gender, parents' education level and parity. Families whose system type could not be reliably identified in our previous study due to excessively small group size were excluded $(8 \% ; n=$ 39) (see ref_blinded, $x x x x$ ). Thus, the final sample of the current study consisted of $n=452$ families, involving $n=447$ maternal and $n=281$ paternal reports. The ethics committees of the participating clinics approved the study at all time-points (T1-T4).

\section{Measures}

Identification of family system types (T1-T3). Family relationships were measured with the Subjective Family Picture Test (Mattejat \& Scholz, 1994) during pregnancy (T1), and when the child was 2 months (T2) and 12 months old (T3). Parents rated four family relationships (mother-to-father, father-to-mother, mother-to-child, and father-to-child) regarding autonomy (four pairs of items; e.g., self-confident-uncertain) and intimacy (four pairs of items; e.g., loving - rejecting) using a 7-point scale.

Factor mixture modeling in Mplus 5 (Muthén \& Muthén, 1998-2012) was used to identify family system types based on relationship ratings of autonomy and intimacy from mothers (24 variables) and fathers (24 variables). To avoid identifying an artificially high number of latent classes due to highly correlating variables, common factors were added for parents' reports (Lubke \& Neale, 2006). Missing values were handled using full information maximum likelihood approach. The first phase of the analysis identified the number of family system types, and the second phase of the analysis identified the number of family system types in which parents' reports were discrepant (or convergent). The number of classes was determined by the Bayesian Information Criterion, which has been shown to be highly reliable criterion in factor mixture modeling (Nylund, Asparouhov, \& Muthén, 2007). 
Running head: PATHWAYS FROM EARLY FAMILY TYPES TO INTERNALIZING

The analysis yielded seven trajectories depicting different family system types. They were described based on the overall levels (i.e., averaged values over the target parents, family subsystems, and reporting parents) and longitudinal changes (T1-T3) in autonomy and intimacy. Altogether, the family system types accounted $63 \%$ and $61 \%$ of the variance in the overall levels, and $13 \%$ and $29 \%$ of the overall longitudinal changes in autonomy and intimacy, respectively (all $p$ 's $<.001$ ). To achieve sufficient statistical power in the current study, we grouped enmeshed quadratic $(n=26)$ and enmeshed declining $(n=32)$ families to one group of enmeshed families, and disengaged $(n=29)$ and escalating crisis $(n=22)$ families to one group of distant families. Thus, the families in the present study represent either cohesive $(n=200)$, discrepant $(n=70)$, enmeshed $(n=58)$, distant $(n=51)$ or authoritarian $(n=72)$ family system types. For a description of the five family system types see Introduction and for more details about the procedure, see ref_blinded (xxxx).

Depression and anxiety (T4). Children's depression (12 items) and anxiety (11 items) were measured using corresponding subscales of the Behavior Assessment System for Children (Reynolds \& Kamphaus, 1992). Both parents reported their child's symptoms using 4-point Likert scale, ranging from 1 (never) to 4 (almost always). Items for each subscale were averaged separately for both parents and showed satisfactory internal reliability for mothers (depression $\alpha=.82$; anxiety $\alpha=.76$ ) and fathers (depression $\alpha=.80$; anxiety $\alpha=$ $.82)$.

Emotion regulation (T4). Child's emotion regulation was measured using the selfregulation subscale of the Emotion Questionnaire (Rydell et al., 2003). The questionnaire consists of 11 vignettes describing emotion-evoking situations for different emotions. We used nine vignettes for negative emotions of fear (e.g., My child gets frightened and worried), anger (e.g., My child gets into a conflict with a peer) and sadness (e.g., A toy is lost or broken). For each vignette, both parents estimated how easily the child was able to calm 
Running head: PATHWAYS FROM EARLY FAMILY TYPES TO INTERNALIZING

down by him- or herself using 5-point Likert scale, ranging from 1 (doesn't apply at all) to 5 (applies very well). All nine items were averaged separately for both parents and showed satisfactory internal reliability for mothers $(\alpha=.88)$ and fathers $(\alpha=.87)$.

Peer exclusion (T4). Peer exclusion was measured using the corresponding subscale of the Child Behavioral Scale (Ladd \& Profilet, 1996). For the purposes of this study four of the eight items were reverse worded to indicate positive peer acceptance (e.g., Child is often accepted to join peer play). Both parents estimated how well the descriptions fit their child on a 4-point Likert scale, ranging from 1 (never) to 4 (almost always). All eight items were averaged separately for both parents and showed satisfactory internal reliability for mothers $(\alpha=.78)$ and fathers $(\alpha=.80)$.

Moderators and background variables. Moderator variables were former infertility $(0=\mathrm{NC}, 1=\mathrm{ART})$, parity $(0=$ primiparity, $1=$ multiparity $)$, parents' averaged education level $(1$ = basic education, 2 = vocational training, $3=$ college level, $4=$ academic level $)$, and child's gender $(0=$ girl, $1=$ boy $)$.

\section{Analytic Strategy}

Statistical analyses were carried out using structural equation modeling in Mplus 7.11 (Muthén \& Muthén, 1998-2012) based on maximum likelihood estimation with robust standard errors. This estimation method handles missing data using full information maximum likelihood. The fit of the models was evaluated with the comparative fit index (CFI), the Tucker-Lewis index (TLI) and the root mean square errors of approximation (RMSEA). Chi-square $(\chi 2)$ was also reported, even though it is inflated with large sample size. As a criterion of acceptable fit, values of $>0.95$ for CFI and $<0.08$ for RMSEA were used (Hooper, Coughlan, \& Mullen, 2008). The fit of nested models was compared with the Satorra-Bentler Scaled chi-square test $(\Delta \chi 2)$. R-squared values were reported to indicate absolute $\left(\mathrm{R}^{2}\right)$ and incremental $\left(\Delta \mathrm{R}^{2}\right)$ variance accounted by the independent variables over 
Running head: PATHWAYS FROM EARLY FAMILY TYPES TO INTERNALIZING

and above the covariates. Standardized coefficients $(\beta)$ were reported for individual paths. Mediation was tested using the delta method, based on the product term between the coefficients (MacKinnon, 2008). The Benjamini-Hochberg procedure was used to protect significance levels against false positive discoveries for each research question (Benjamini \& Hochberg, 1995). Bias corrected bootstrapping was used to estimate $95 \%$ confidence intervals (CIs) under maximum likelihood estimation.

To test the direct and moderated effects of family system types on child outcomes, we built a model in which early family system types predicted children's anxiety, depression, emotion regulation and peer exclusion ( $a_{1}$ and $a_{2}$-paths in Figure 2). Two indicator variables, one from each parent, were used to form the latent variables for each child outcome. Family system types were dummy coded to represent contrasts between Cohesive and other family system types ( 0 vs 1 ). Wald test was used to test differences between the path coefficients (i.e., specific effects of family system types). To test the moderated effects, we computed interaction terms between the family system type variables and former infertility, parity, parental education level, and child's gender (b-paths in Figure 2).

To test the mediated effects we added the regression paths from emotion regulation and peer exclusion to depression and anxiety (c-paths in Figure 2). Main effects of family system types (a-paths in Figure 2) and significant interaction terms (b-paths in Figure 2) were retained in the model to control for their effects and to test moderated mediation. All models included parental education level, former infertility, parity and child's gender as covariates.

\section{Results}

\section{Measurement Model and Tests of Invariance}

Combined measurement model, consisting of latent constructs of children's anxiety, depression, emotion regulation, peer exclusion and their covariances, had acceptable fit, $\chi 2(8)$ $=7.01, p=.535, \mathrm{CFI}=1.000, \mathrm{TLI}=1.000, \mathrm{RMSEA}<0.01 ; 90 \% \mathrm{CI}[0.00,0.05]$. To ensure 
Running head: PATHWAYS FROM EARLY FAMILY TYPES TO INTERNALIZING

that the subsequent results were not biased because of differences in factor loadings between mothers (range: .61-.81) and fathers (range: .56-.72), all the factor loadings were fixed to one. This was acceptable, as it did not decrease model fit, $\Delta \chi 2(4)=0.631, p=.959$.

Multiple group analyses confirmed equal covariances between latent constructs (i.e., structural invariance) between formerly infertile and naturally conceiving families, $\Delta \chi 2(6)=$ $1.82, p=.936$, between boys and girls, $\Delta \chi 2(6)=3.06, p=.801$, and between primi- and multiparous families, $\Delta \chi 2(6)=4.18, p=.653$. Thus, in subsequent analyses, these subgroups were analyzed together.

As described in the introduction and methods, we had grouped two family system types representing enmeshed and distant families together to achieve sufficient group sizes. We tested the plausibility of this grouping by examining whether the grouped family system types had similar effects on child outcomes ( $a_{1}$ and $a_{2}$-paths in Figure 2). The results showed that the path coefficients could be constrained to be the same between the two original enmeshed, Wald $(4)=4.49, p=.344$, and between the two original distant, $\operatorname{Wald}(4)=7.38, p$ $=.120$, family system types. Thus, the grouping was maintained in subsequent analyses.

\section{Descriptive Statistics}

Means, standard deviations and latent correlations between the study variables are shown in Table A1. Enmeshed families were more often primiparous (74.4\%) and distant families less often primiparous $(26.6 \%)$ compared to the other family system types, $\chi^{2}(4)=$ 26.75, $\mathrm{p}<.001$. Based on the guidelines provided by Reynolds and Kamphaus (1992), we considered $14.0 \%$ and $15.8 \%$ of the children to be at-risk for $(\mathrm{T} \geq 60)$, and $3.1 \%$ and $2.5 \%$ of the children to have clinically significant symptoms of $(T \geq 70)$ anxiety and depression, respectively. As shown in Table A2, $20 \%$ to $25 \%$ of the children in discrepant, enmeshed or distant families were at-risk, whereas only $5 \%$ to $11 \%$ of the children in cohesive and authoritarian families were at-risk for anxiety and depression. We further examined the 
Running head: PATHWAYS FROM EARLY FAMILY TYPES TO INTERNALIZING

associations between background variables and child outcomes, shown in Table 1 (see Background variables). The results showed that primiparity predicted heightened anxiety, depression, and inefficient emotion regulation. Background variables accounted for $13.4 \%$ of anxiety, $5.0 \%$ of depression, $3.3 \%$ of peer exclusion and $6.8 \%$ of emotion regulation.

\section{Direct Pathways from Family System Types to Child Outcomes}

Regarding internalizing symptoms, the results presented in Table 1 (see Family system types) showed that discrepant, enmeshed and distant families predicted children's heightened anxiety and depression. Against the specificity hypothesis, these effects of discrepant, enmeshed and distant families were similar on anxiety and depression, Wald $(4)=1.07, p=$ .899. Authoritarian family type did not predict children's anxiety or depression. These direct effects accounted for $9.7 \%$ of anxiety and $6.5 \%$ of depression over and above the covariates.

Regarding socioemotional development, the results presented in Table 1 showed that enmeshed and distant families predicted children's inefficient emotion regulation. Their effects on emotion regulation were similar, Wald $(1)=0.34, p=.563$. Discrepant or authoritarian families did not predict children's emotion regulation, and unexpectedly, none of the family system types predicted children's peer exclusion. These direct effects accounted for $8.7 \%$ of emotion regulation and $1.0 \%$ of peer exclusion over and above the covariates.

\section{[Insert Table 1 about here]}

\section{Moderated Pathways from Family System Types to Child Outcomes}

The results supported the contextual factors hypothesis by showing that former infertility, Wald $(16)=27.21, p=.039$, parity, Wald $(16)=32.41, p=.009$, and parental education, Wald $(16)=30.65, p=.015$, moderated the effects of family system types on child outcomes. Child's gender did not have a protective or vulnerability role, Wald $(16)=13.51, p$ $=.636$.

Parent's former infertility moderated the effects of distant families on children's 
Running head: PATHWAYS FROM EARLY FAMILY TYPES TO INTERNALIZING

depression, $\beta=0.59, S E=0.21, p=.005,95 \%$ CI $[0.07,0.38]$. As shown in Figure 3, distant families did not predict children's depression in families with infertility history, but predicted children's heightened depression in naturally conceiving families.

Parity moderated the effects of enmeshed families on children's peer exclusion, $\beta=-$ 0.20, $S E=0.07, p=.004,95 \%$ CI [-0.53, -0.08]. As shown in Figure 4, enmeshed families did not predict children's peer exclusion when the child had older siblings, but predicted heightened peer exclusion when the child was the first born.

Finally, parental education level moderated the effects of authoritarian families on children's emotion regulation, $\beta=-0.19, S E=0.07, p=.003,95 \%$ CI $[-0.39,-0.07]$, and depression, $\beta=0.21, S E=0.07, p=.001,95 \%$ CI $[0.05,0.20]$. As shown in Figure 5, authoritarian families predicted children's inefficient emotion regulation only when the parents had high education level. Similarly, authoritarian families predicted children's depression only when the parents had high education level.

The moderated effects accounted for $7.9 \%$ of depression, $7.7 \%$ of anxiety, $6.8 \%$ of emotion regulation and $6.4 \%$ of peer exclusion over and above the direct effects and covariates. The model had acceptable fit, $\chi 2(102)=121.27, p=.094, \mathrm{CFI}=0.977$, TLI $=$ 0.950, RMSEA $=0.02 ; 90 \%$ CI $[0.00,0.04]$.

\section{[Insert Figures 3, 4 and 5 about here]}

\section{Mediated Pathways via Emotion Regulation and Peer Exclusion}

The path coefficients in the mediation model, shown in Figure 6, indicated that mediated pathways were possible from family system types via children's emotion regulation to depression, but not to anxiety. In line with the emotion regulation hypothesis, the detrimental effects of enmeshed, $z=0.15, S E=0.06, p=.010,95 \%$ CI $[0.06,0.36]$, and distant families, $z=0.11, S E=0.05, p=.034,95 \% \mathrm{CI}[0.03,0.27]$, on children's depression were both mediated via inefficient emotion regulation. Furthermore, the interaction effect 
Running head: PATHWAYS FROM EARLY FAMILY TYPES TO INTERNALIZING

between authoritarian families and parental education on children's depression was mediated via inefficient emotion regulation, $z=0.11, S E=0.05, p=.019,95 \%$ CI $[0.04,0.25]$. In other words, only when the parents had high education level the authoritarian families predicted children's inefficient emotion regulation which led to heightened depression.

Against the emotion regulation hypothesis, the effect of discrepant families and the effect of distant families with naturally conceiving (NC) parents on children's internalizing symptoms were not mediated via emotion regulation. Instead, as shown in Figure 6, discrepant families directly predicted children's heightened anxiety, and distant NC families directly predicted children's heightened depression. Finally, against our hypotheses, peer exclusion did not predict either depression or anxiety, indicating that it did not mediate between the family system types and internalizing symptoms.

\section{[Insert Figure 6 about here]}

\section{Discussion}

The aim of this study was to model how early family systems, contextual factors and socioemotional processes together shape children's internalizing symptoms. We used a novel approach to identify families as complex and dynamic family system types, composed of parental and marital trajectories from pregnancy to child's infancy. Against the specificity hypothesis, the results showed that discrepant, enmeshed and distant families similarly predicted children's heightened anxiety and depression. In line with the contextual factors hypothesis, the results showed that former infertility, parity, and parental education level moderated some effects of the family system types. Finally, in line with the emotion regulation hypothesis, the results showed that emotion regulation mediated the effects of enmeshed, distant and authoritarian families on children's depression. Against the hypothesis, however, the effects of discrepant families on children's anxiety occurred irrespective of children's emotion regulation efficiency. Altogether, the results suggest that early family 
Running head: PATHWAYS FROM EARLY FAMILY TYPES TO INTERNALIZING

systems, together with contextual factors, predict children's internalizing symptoms, and children's emotion regulation largely accounts for the effects on depression.

In line with the evolutionary models of psychopathology, we hypothesized that early family system types would have specific effects on children's anxiety and depression, reflecting different strategies children use to adapt to their family environments. However, against this specificity hypothesis, we found that enmeshed, distant and discrepant families similarly predicted both anxiety and depression. These results concur with the recent metaanalysis of parenting showing little evidence of symptom specificity (Yap \& Jorm, 2015). Thus, it seems that very different family problems, ranging from emotionally distant to overly enmeshed, can similarly lead to heightened risk of internalizing problems. This general effect could be due to both psychological and psychophysiological mechanisms, involving, for example, children's increased insecure representations of the family (Davies \& Martin, 2013) and early developmental alterations of psychophysiological stress regulation (e.g., HPA axis; Brumariu \& Kerns, 2010). Finally, it is possible that children's temperamental characteristics, such as behavioral inhibition, or later life experiences, such as interpersonal threats and losses, shape the more general early vulnerability into specific disorders (Brumariu \& Kerns, 2010).

We also hypothesized that former infertility and other contextual factors would interact with family types in predicting children's internalizing symptoms and socioemotional development. In line with this contextual factors hypothesis, former infertility provided protection against depression in distant families, and having siblings in the family protected children against peer exclusion in enmeshed families. These results can be understood in terms of contextual factors affecting family boundaries, which regulate how family subsystems influence each other (e.g., Sturge-Apple, et al., 2014). Formerly infertile parents often have high motivation for parenthood and tend to be protective towards their children 
Running head: PATHWAYS FROM EARLY FAMILY TYPES TO INTERNALIZING

(Barnes et al., 2004). In distant ART families this may help the parents to maintain sensitive parenting despite conflicts in the marital subsystem, thus protecting children's mental health. Regarding enmeshed families, it is possible that older siblings help to strengthen boundaries between the parental and sibling subsystems. This may protect children from the detrimental family interactions, such as parent-child role reversals. Interestingly, the protective role of siblings was restricted to social development, and did not extend to internalizing problems.

Regarding the moderating role of parental education, we found that the authoritarian family type predicted children's depression and inefficient emotion regulation only in families with high parental education level. This intriguing result concurs with the metaanalysis by McLeod, Weisz et al. (2007) which showed that high parental education level increased the effects of parental rejection on children's depression. Research suggests that parents with high socioeconomic status value highly their children's autonomy but may provide somewhat limited emotional support for them (Luthar, 2003). Thus, it is possible that the combination of authoritarian family type and high parental education level result in rigid family climate, involving, for example, low nurturance and undue emphasis on discipline and routines (Arnott \& Brown, 2013). Such family environment could hamper children's developmental needs for both autonomy and intimacy, with detrimental consequences on emotional well-being and mental health (Luyten \& Blatt, 2011).

In line with the emotion regulation hypothesis, the results showed that inefficient emotion regulation mediated the effects of enmeshed, distant and authoritarian families on children's depression. These results support the emotion regulation model of psychopathology, suggesting that family dysfunctions impair children's mental health through emotion regulation development (e.g., Morris et al., 2007). Our prospective study extend existing knowledge by demonstrating the importance of very early holistic family systems. Furthermore, our results help explain the equifinality paradox in developmental 
Running head: PATHWAYS FROM EARLY FAMILY TYPES TO INTERNALIZING

family research, by suggesting that inefficient emotion regulation is a common developmental consequence of various family dysfunctions. Such explanation is in line with both the attachment (Thompson \& Meyer, 2007) and emotional security (Davies \& Martin, 2013) theories, which posit that early sensitive caregiving and security in the family context are essential for the development of emotion regulation. When these are lacking, children develop self-protective strategies rather than more efficient ways of emotion regulation.

Interestingly, against the emotion regulation hypothesis, the results showed that distant families with naturally conceiving (NC) parents directly predicted heightened depression, and discrepant families (both ART and NC) directly predicted heightened anxiety. Although not hypothesized, these results provide some indication of specific effects of families on children's anxiety and depression, occurring irrespective of emotion regulation efficiency. As suggested by the emotional security theory (Davies \& Martin, 2013), it is possible that children in distant NC families acquire a demobilizing strategy to defuse and avoid threatprovoking family conflicts, involving social withdrawal, submissiviness and blunted emotions. While such a strategy may have some adaptive value in the context of distant families, it is likely maladaptive in many other contexts and increases risk for depression.

Only a few studies have examined how parental discrepancies in family perceptions predict children's mental health (e.g., Johnson, 2005). Our results suggest that early parental discrepancy may have specific effect on children's anxiety. While the exact reason for this is unclear, there are a few plausible explanations. First, research suggests that father-child interactions, involving e.g., rough-and-tumble play, have a special role in teaching the child to cope with challenges and uncertainty (Möller, Nikolić, Majdandžić, \& Bögels, 2016). In discrepant families fathers were more pessimistic than mothers in their family perceptions. Thus, it is possible that fathers in discrepant families tend to provoke a sense of vulnerability in their children, thereby increasing children's cautiousness and anxiety. Second, it is 
Running head: PATHWAYS FROM EARLY FAMILY TYPES TO INTERNALIZING

possible that the lack of shared parental perceptions hinder the coordination of family interactions (Johnson, 2005), especially complex ones, involving both parents and the child (Favez et al., 2012). For example, entrapment between the parents in a conflict could increase children's ambivalence and anxiety, without necessarily disrupting their emotion regulation. Unexpectedly, children's emotion regulation did not predict anxiety and thus did not mediate the effects of early family system types on children's anxiety. We assessed emotion regulation as an ability to down-regulate negative emotions. Our result may thus partially be explained by previous research suggesting that anxiety is more strongly associated with high reliance on inefficient (e.g., rumination) rather than low reliance on efficient (e.g., reappraisal) emotion regulation strategies (Aldao, Nolen-Hoeksema, \& Schweizer, 2010). Further studies are needed to test whether some specific emotion regulation strategies mediate between early family problems and later anxiety. Finally, against our hypothesis, peer exclusion did not predict children's internalizing symptoms. It is important to note, however, that in our correlation analyses peer exclusion was associated with both anxiety and depression, but these disappeared when peer exclusion and emotion regulation were modeled as parallel mediators. This suggests that emotion regulation and peer exclusion share some common variance, but the unique variance of emotion regulation is more important in mediating between early family system types and later internalizing symptoms.

\section{Limitations}

Despite having relatively large sample and using rich information to identify the family system types, our study has several limitations. First, we were unable to control the potential continuity of the family system types during the children's later developmental phases. Thus, conclusions about age-specificity should be made with caution. Second, despite the prospective design over 8 years, the child outcomes were assessed at the same time point. Having more assessment points would have allowed to more reliably model the child- and 
Running head: PATHWAYS FROM EARLY FAMILY TYPES TO INTERNALIZING

family-related mediating mechanisms. Third, our study was based on parent's reports, and attrition at the child's age of 7-8 years was larger among fathers than among mothers. Despite using structural equation modeling to reduce measurement error and full information maximum likelihood to handle missingness, it is possible that some reporter biases have occurred. For example, parents may have shared some biased perceptions about their families and the child. Observational methods as well as child self-reports could have yielded more objective results. Finally, the participating parents were relatively highly educated and only few children experienced clinical levels of anxiety and depression. Hence, some caution is warranted when generalizing our results to more disadvantaged and clinical populations.

\section{Conclusions}

Our results emphasize the significance of whole family systems, including both mothers and fathers as well as the marital and parenting subsystems, for children's early development. Further, our results indicate that emotion regulation is an important developmental mechanism linking early family dysfunctions to children's depression. This can help to explain equifinality in developmental family research, by suggesting that various types of family problems similarly disrupt children's emotion regulation development. Intriguingly, our results also suggest that parental discrepancies in family perceptions may have a specific role on children's anxiety. This calls for further research on the topic, because specific family predictors of children's anxiety have not been very well recognized (Möller et al., 2016; Yap \& Jorm, 2015). As practical implications, our results help to understand and identify family risks in transition to parenthood. They highlight the importance of early preventive help aimed for whole families, and suggest that children with adverse family experiences, especially those with depressive symptoms, may benefit from therapeutic interventions focusing on emotion regulation. 
Running head: PATHWAYS FROM EARLY FAMILY TYPES TO INTERNALIZING

\section{References}

Abravanel, B. T., \& Sinha, R. (2015). Emotion dysregulation mediates the relationship between lifetime cumulative adversity and depressive symptomatology. Journal of Psychiatric Research, 61, 89-96. doi:10.1016/j.jpsychires.2014.11.012

Aldao, A., Nolen-Hoeksema, S., \& Schweizer, S. (2010). Emotion-regulation strategies across psychopathology: A meta-analytic review. Clinical Psychology Review, 30(2), 217-37. doi:10.1016/j.cpr.2009.11.004

Arnott, B., \& Brown, A. (2013). An exploration of parenting behaviours and attitudes during early infancy: Association with maternal and infant characteristics. Infant and Child Development, 22(4), 349-361. doi:10.1002/icd.1794

Barnes, J., Sutcliffe, A. G., Kristoffersen, I., Loft, A., Wennerholm, U., Tarlatzis, B. C., ... Bonduelle, M. (2004). The influence of assisted reproduction on family functioning and children's socio-emotional development: results from a European study. Human Reproduction, 19(6), 1480-7. doi:10.1093/humrep/deh239

Benjamini, Y., \& Hochberg, Y. (1995). Controlling the false discovery rate: A practical and powerful approach to multiple testing. Journal of the Royal Statistical Society. Series B (Methodological), 57(1), 289-300. doi:10.2307/2346101

Bergman, L. R., \& Magnusson, D. (1997). A person-oriented approach in research on developmental psychopathology. Development and Psychopathology, 9(9), 291-319.

Brumariu, L. E., \& Kerns, K. A. (2010). Parent-child attachment and internalizing symptoms in childhood and adolescence: a review of empirical findings and future directions. Development and Psychopathology, 22, 177-203. doi:10.1017/S0954579409990344

Buehler, C., Anthony, C., Krishnakumar, A., Stone, G., Gerard, J., \& Pemberton, S. (1997). Interparental conflict and youth problem behaviors : A meta-analysis. Journal of Child and Family Studies, 6(2), 233-247. doi:10.1023/A:1025006909538 
Running head: PATHWAYS FROM EARLY FAMILY TYPES TO INTERNALIZING

Cairo, S., Darwiche, J., Tissot, H., Favez, N., Germond, M., Guex, P., de Roten, Y., Frascaloro, F. \& Despland, J. N. (2012). Family interactions in IVF families: Change over the transition to parenthood. Journal of Reproductive and Infant Psychology, 30, 520. doi: $\underline{10.1080 / 02646838.2012 .669830}$

Cox, M. J., \& Paley, B. (2003). Understanding families as systems. Current Directions in Psychological Science, 12(5), 193-196. doi:10.1111/1467-8721.01259

Davies, P. T., \& Martin, M. J. (2013). The reformulation of emotional security theory: The role of children's social defense in developmental psychopathology. Development and Psychopathology, 25, 1435-54. doi:10.1017/S0954579413000709

Eley, T. C., Stevenson, J. (2000). Specific life events and chronic experiences differentially associated with depression and anxiety in young twins. Journal of Abnormal Child Psychology, 28(4), 383-394. doi: 10.1023/A:1005173127117

Favez, N., Lopes, F., Bernard, M., Frascarolo, F., Lavanchy Scaiola, C., Corboz-Warnery, A., \& Fivaz-Depeursinge, E. (2012). The development of family alliance from pregnancy to toddlerhood and child outcomes at 5 years. Family Process, 51(4), 542-556.

Groh, A. M., Fearon, R. P., Bakersman-Kranenburg, M. J., van IJzendoorn, M. H., Steele, R. D., Roisman, G. I. (2014). The significance of attachment security for children's social competence with peers: a meta-analytic study. Attachment and Human Development, 16, 103-136. doi: 10.1080/14616734.2014.883636

Harwood, K., McLean, N., \& Durkin, K. (2007). First-time mothers' expectations of parenthood: What happens when optimistic expectations are not matched by later experiences? Developmental Psychology, 43(1), 1-12. doi:10.1037/0012-1649.43.1.1

Hooper, D., Coughlan, J., \& Mullen, M. (2008). Structural equation modeling: guidelines for determining model fit. Electronic Journal of Business Research Methods, 6(1), 53-60.

Johnson, V. K. (2005). Family process and family structure in children's adaptation to school. 
Running head: PATHWAYS FROM EARLY FAMILY TYPES TO INTERNALIZING

In The family context of parenting in children's adaptation to elementary school. (pp. 255-274). doi:10.4324/9781410612885

Kim, J., \& Cicchetti, D. (2010). Longitudinal pathways linking child maltreatment, emotion regulation, peer relations, and psychopathology. Journal of Child Psychology and Psychiatry, 6, 706-716. doi:10.1111/j.1469-7610.2009.02202.x

Ladd, G. W., \& Profilet, S. M. (1996). The child behavior scale: A teacher-report measure of young children's aggressive, withdrawn, and prosocial behaviors. Developmental Psychology, 32(6), 1008-1024. doi:10.1037/0012-1649.32.6.1008

Lindahl, K. M., Malik, N. M., Kaczynski, K., \& Simons, J. S. (2004). Couple power dynamics, systemic family functioning, and child adjustment: A test of a mediational model in a multiethnic sample, 609-630. doi:10.1017/S0954579404004699

Lorensen, M., Wilson, M. E., \& White, M. A. (2004). Norwegian families: transition to parenthood. Health Care for Women International, 25(4), 334-48.

Lubke, G., \& Neale, M. C. (2006). Distinguishing between latent classes and continuous factors: Resolution by maximum likelihood? Multivariate Behavioral Research, 41(4), 499-532. doi:10.1207/s15327906mbr4104_4

Luyten, P., \& Blatt, S. J. (2011). Integrating theory-driven and empirically-derived models of personality development and psychopathology: A proposal for DSM V. Clinical Psychology Review. doi:10.1016/j.cpr.2010.09.003

MacKinnon, D. P. (2008). Introduction to statistical mediation analysis. NY: Lawrence Erlbaum Associates.

Mattejat, F., \& Scholz, M. (1994). Das subjektive Familienbild [Subjective Family Picture Test]. Göttingen, Germany: Hogrefe.

McLeod, B. D., Weisz, J. R., \& Wood, J. J. (2007). Examining the association between parenting and childhood depression: a meta-analysis. Clinical Psychology Review, 27(8), 
Running head: PATHWAYS FROM EARLY FAMILY TYPES TO INTERNALIZING

986-1003. doi:10.1016/j.cpr.2007.03.001

McLeod, B. D., Wood, J. J., \& Weisz, J. R. (2007). Examining the association between parenting and childhood anxiety: a meta-analysis. Clinical Psychology Review, 27(2), 155-72. doi:10.1016/j.cpr.2006.09.002

Morris, A. S., Silk, J. S., Steinberg, L., Myers, S. S., \& Robinson, L. R. (2007). The Role of the family context in the development of emotion regulation. Social Development, 16(2), 361-388. http://doi.org/10.1111/j.1467-9507.2007.00389.x

Muthén, L.K., \& Muthén, B.O. (1998-2012). Mplus user's guide (7th ed.). Los Angeles, CA. Möller, E. L., Nikolić, M., Majdandžić, M., \& Bögels, S. M. (2016). Associations between maternal and paternal parenting behaviors, anxiety and its precursors in early childhood: A meta-analysis. Clinical Psychology Review, 45, 17-33. doi: 10.1016/j.cpr.2016.03.002

Nylund, K. L., Asparouhov, T., \& Muthén, B. (2007). Deciding on the number of classes in latent class analysis and growth mixture modeling: A Monte Carlo simulation study. Structural Equation Modeling, 14, 535-569. doi:10.1080/10705510701575396

Stevens, A. \& Price, J. (2000). Evolutionary psychiatry (2 $2^{\text {nd }}$ ed.). London: Routledge.

Reijntjes, A., Kamphuis, J. H., Prinzie, P., \& Telch, M. J. (2010). Peer victimization and internalizing problems in children: A meta-analysis of longitudinal studies. Child Abuse and Neglect, 34(4), 244-252. doi:10.1016/j.chiabu.2009.07.009

Reynolds, C. R., \& Kamphaus, R. W. (1992). Behavior Assessment System for Children (BASC). Circle Pines, MN: AGS.

Rydell, A., Berlin, L., \& Bohlin, G. (2003). Emotionality, emotion regulation, and adaptation among 5- to 8-year-old children, 3(1), 30-47. doi:10.1037/1528-3542.3.1.30

Sloman, L., Farvolden, P., Gilbert, P., \& Price, J. (2006). The interactive functioning of anxiety and depression in agonistic encounters and reconciliation. Journal of Affective Disorders, 90, 93-99. doi:10.1016/j.jad.2005.12.001 
Running head: PATHWAYS FROM EARLY FAMILY TYPES TO INTERNALIZING

Statistics Finland. (2013). StatFin [Online database]. Retrieved from http://www.stat.fi/

Sturge-Apple, M. L., Davies, P. T., Cicchetti, D., \& Fittoria, M. G. (2014). A typology of interpartner conflict and maternal parenting practices in high-risk families: Examining spillover and compensatory models and implications for child adjustment. Development and Psychopathology, 26, 1-16. doi:10.1017/S0954579414000509

Suveg, C., Morelen, D., Brewer, G. A., \& Thomassin, K. (2010). The emotion dysregulation model of anxiety: a preliminary path analytic examination. Journal of Anxiety Disorders, 24(8), 924-30. doi:10.1016/j.janxdis.2010.06.018

Tamis-LeMonda, C. S., Shannon, J. D., Cabrera, N. J., \& Lamb, M. E. (2004). Fathers and mothers at play with their 2- and 3-year-olds: Contributions to language and cognitive development. Child Development, 75, 1806-1820. doi:10.1111/j.14678624.2004.00818.x

Thompson, R. A. \& Meyer, S. (2007). Socialization of emotion regulation in the family. In James K. Gross (Ed.), Handbook of emotion regulation (pp. 249-268). New York: Guildford Press.

Twenge, J. M., Campbell, W. K., \& Foster, C. A. (2003). Parenthood and marital satisfaction: A meta-analytic review. Journal of Marriage and Family, 65, 574-583. doi:10.1111/j.1741-3737.2003.00574.x

Wilson, C. L., Fisher, J. R., Hammarberg, K., Amor, D. J., Halliday, J. L. (2011). Looking downstream: a review of the literature on physical and psychosocial health outcomes in adolescents and young adults who were conceived by ART. Human Reproduction, 26(6), 1209-1219. doi: 10.1093/humrep/der041

Yap, M. B. H., Jorm, A. F. (2015). Parental factors associated with childhood anxiety, depression and internalizing problems: A systematic review and meta-analysis. Journal of Affective Disorders, 175, 424-440. doi:10.1016/j.jad.2015.01.050 
Table 1. Effects of Background Variables and Early Family System Types on Children's Anxiety and Depression Symptoms, Emotion Regulation and Peer Exclusion.

\begin{tabular}{|c|c|c|c|c|c|c|c|c|c|c|c|c|c|c|c|c|}
\hline & \multicolumn{4}{|c|}{ Anxiety } & \multicolumn{4}{|c|}{ Depression } & \multicolumn{4}{|c|}{ Emotion Regulation } & \multicolumn{4}{|c|}{ Peer Exclusion } \\
\hline & $\bar{\beta}$ & $S E$ & $p$ & $95 \% \mathrm{CI}$ & $\bar{\beta}$ & $S E$ & $p$ & $95 \% \mathrm{CI}$ & $\bar{\beta}$ & $S E$ & $p$ & $95 \% \mathrm{CI}$ & $\bar{\beta}$ & $S E$ & $p$ & $95 \% \mathrm{CI}$ \\
\hline \multicolumn{17}{|c|}{ Background variables } \\
\hline $\begin{array}{l}\text { Former } \\
\text { infertility }\end{array}$ & -0.17 & 0.08 & $(.020)$ & {$[-0.12,0.01]$} & -0.15 & 0.07 & $(.020)$ & {$[-0.11,0.01]$} & -0.07 & 0.06 & .300 & {$[-0.11,0.03]$} & 0.09 & 0.07 & .190 & {$[-0.04,0.18]$} \\
\hline Multiparity & -0.39 & 0.08 & $<.001$ & {$[-0.21,-0.09]$} & -0.21 & 0.07 & .001 & {$[-0.13,-0.03]$} & 0.23 & 0.07 & $<.001$ & {$[0.08,0.30]$} & -0.08 & 0.06 & .193 & {$[-0.11,0.03]$} \\
\hline $\begin{array}{l}\text { Parental } \\
\text { education }\end{array}$ & -0.01 & 0.07 & .904 & {$[-0.04,0.03]$} & -0.12 & 0.06 & .057 & {$[-0.06,0.00]$} & 0.03 & 0.07 & .747 & {$[-0.06,0.08]$} & -0.15 & 0.06 & $(.012)$ & {$[-0.09,-0.01]$} \\
\hline $\begin{array}{l}\text { Gender } \\
\text { (boy) }\end{array}$ & 0.05 & 0.07 & .539 & {$[-0.04,0.07]$} & -0.01 & 0.07 & .925 & {$[-0.05,0.05]$} & -0.15 & 0.07 & $(.022)$ & {$[-0.23,-0.02]$} & 0.08 & 0.06 & .169 & {$[-0.03,0.12]$} \\
\hline
\end{tabular}

Family system types

$\begin{array}{lllllllllllllllllll}\text { Authoritarian } & 0.03 & 0.07 & .666 & {[-0.06,0.09]} & 0.06 & 0.06 & .391 & {[-0.04,0.10]} & -0.13 & 0.07 & .057 & {[-0.29,0.01]} & -0.01 & 0.07 & .982 & {[-0.10,0.10]} \\ \text { Discrepant } & 0.23 & 0.08 & .002 & {[0.05,0.19]} & 0.16 & 0.07 & .012 & {[0.02,0.15]} & -0.09 & 0.06 & .141 & {[-0.23,0.03]} & 0.04 & 0.07 & .592 & {[-0.08,0.13]} \\ \text { Enmeshed } & 0.22 & 0.08 & .004 & {[0.04,0.20]} & 0.21 & 0.08 & .004 & {[0.04,0.21]} & -0.28 & 0.08 & .000 & {[-0.50,-0.16]} & 0.13 & 0.07 & (.047) & {[0.01,0.21]} \\ \text { Distant } & 0.23 & 0.08 & .005 & {[0.04,0.24]} & 0.19 & 0.07 & .004 & {[0.04,0.20]} & -0.21 & 0.08 & .005 & {[-0.46,-0.10]} & 0.02 & 0.06 & .837 & {[-0.09,0.12]}\end{array}$

$\overline{\text { Note}}$. The model including both background variables and family sytem types showed acceptable fit, $\chi 2(54)=57.10, p=.361, \mathrm{CFI}=.996, \mathrm{TLI}=$ Anxiety and Depression Symptoms, Emotion Regulation and Peer Exclusion.

.

Anxiety

Depression Emotion Regulation

Background variables

infertility

Multiparity

Parental

\footnotetext{
.990, RMSEA $=0.01 ; 90 \%$ CI $[0.00-0.03] . P$-values in parentheses refer to nonsignificance according to the Benjamini-Hochberg correction.
}

(boy)

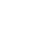

(1)

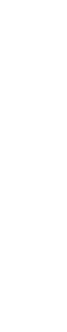

.


Figure 1. Family system types as trajectories from pregnancy (T1) to child's ages of 2 months (T2) and 12 months (T3). Adapted from [source_blinded]. Copyright 20xx by xxxx.

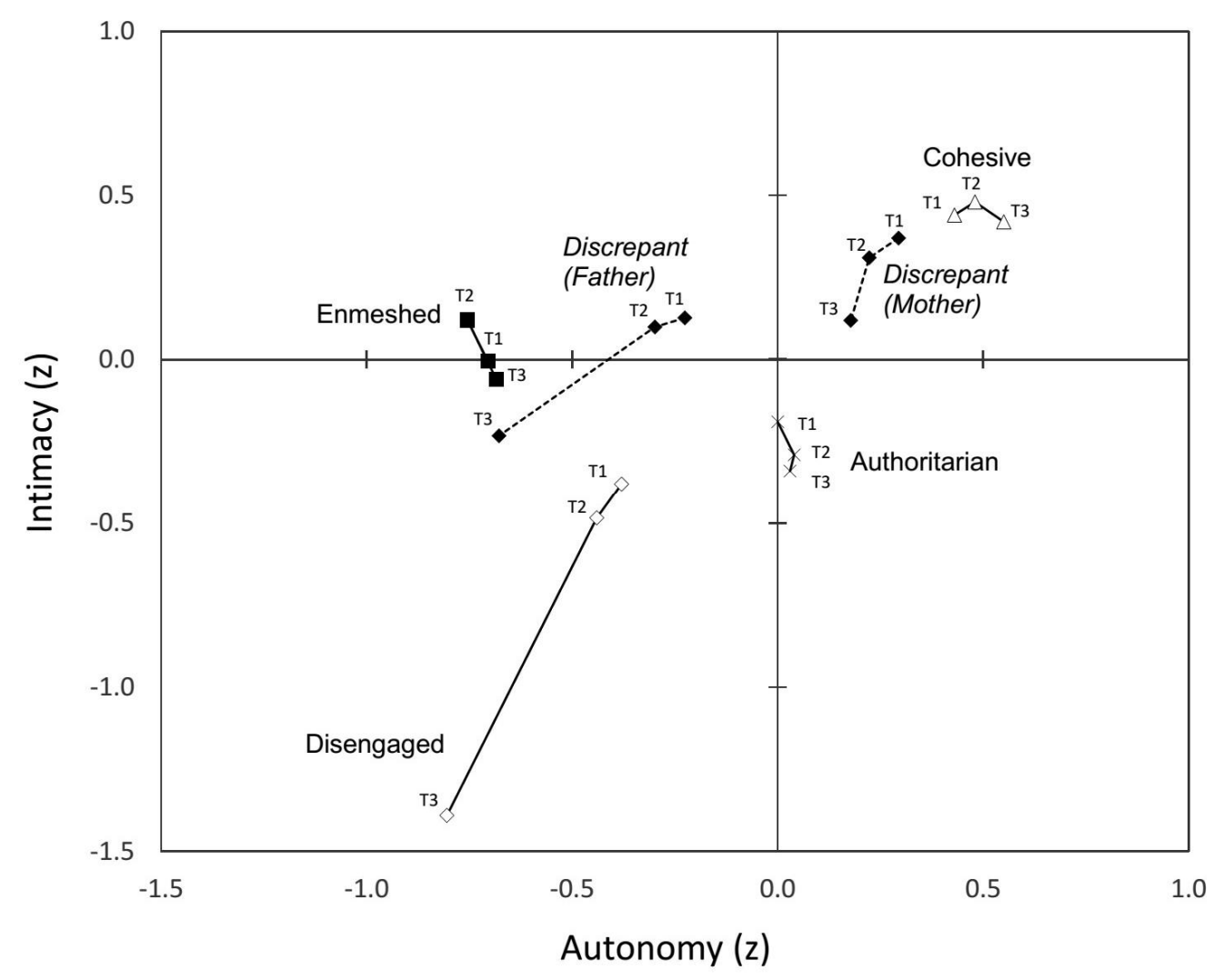

Note. Values are averaged over the parent (father or mother), relationship (parental or marital), and reporter (father or mother), providing a

simplified overview of the family system types. However, separate values are presented for mother's and father's reports for discrepant families, marked with dashed line. 
Figure 2. Conceptual Model Depicting Direct, Moderated and Mediated Pathways from Early Family System Types (T1-T3) to Children's Depression and Anxiety (T4).

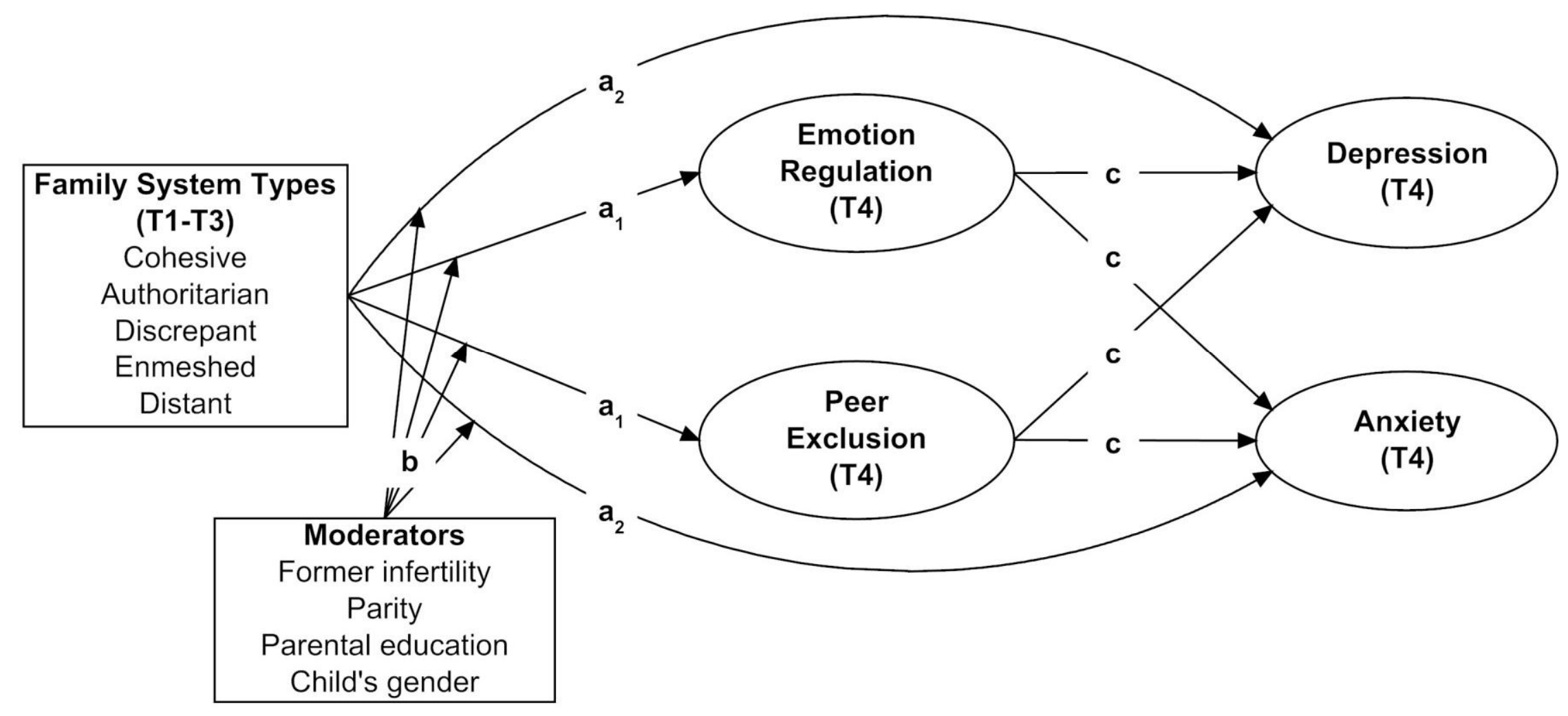

Note. $\mathrm{T} 1=2^{\text {nd }}$ trimester of pregnancy; T2 $=$ Child's age of 2 months; $\mathrm{T} 3=$ Child's age of 12 months; T4 = Child's age of 7-8 years. 
Figure 3. Former Infertility Moderates the E ffects of Distant (vs Cohesive) Families on Children's Depression.

Figure 3. Former Infertility Moderates the Effects of Distant (vs Cohesive) Families on Children's Depression.

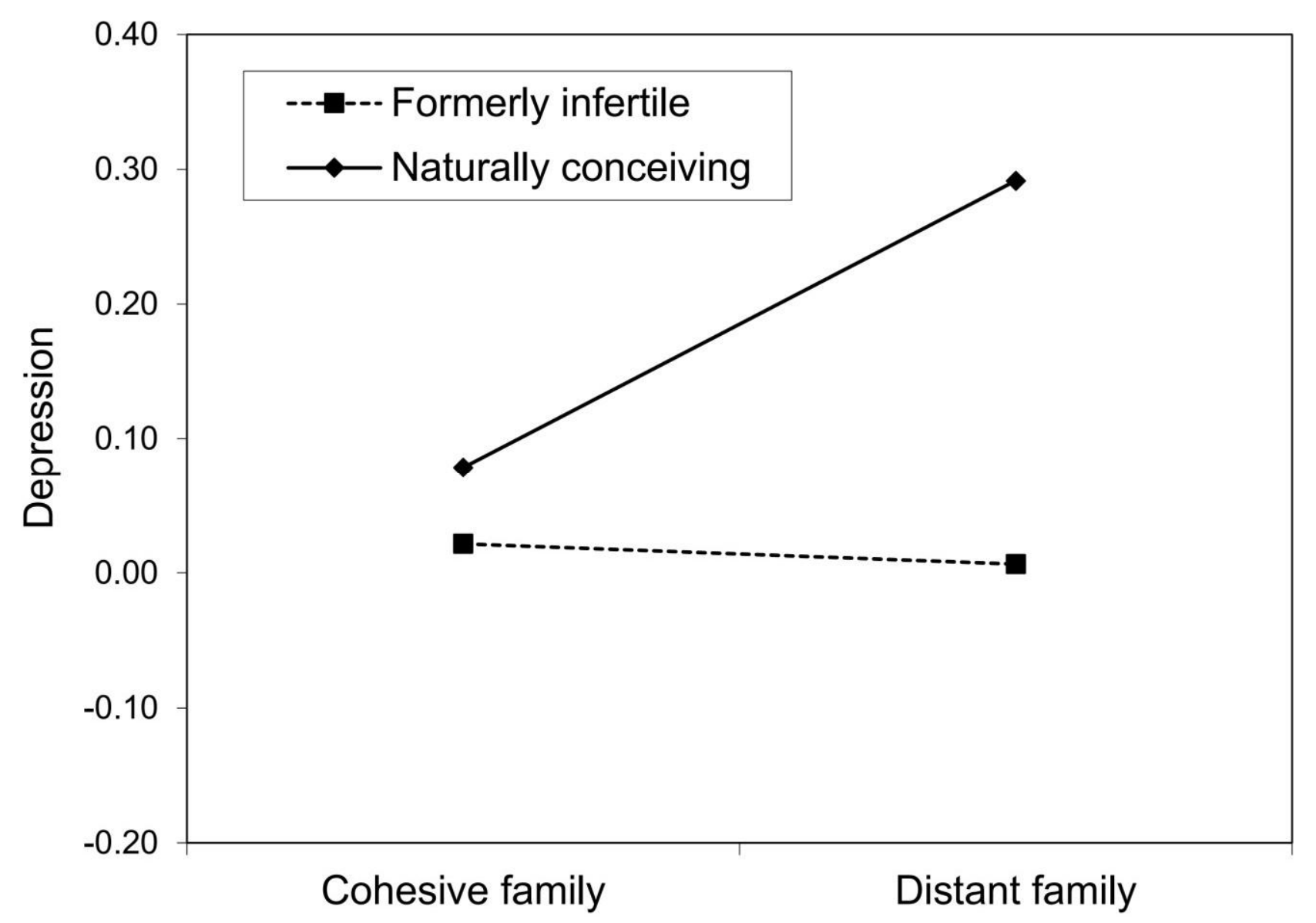

Note. Among naturally conceiving (NC) parents distant family predicted children's heightened depression, $\beta=0.38, S E=0.11, p<.001$, whereas among formerly infertile (ART) parents distant family did not predict depression, $\beta=0.11, S E=0.13, p=.400$. 
Figure 4. Parity Moderates the Effects of Enmeshed (vs Cohesive) Families on Children's Peer Exclusion.

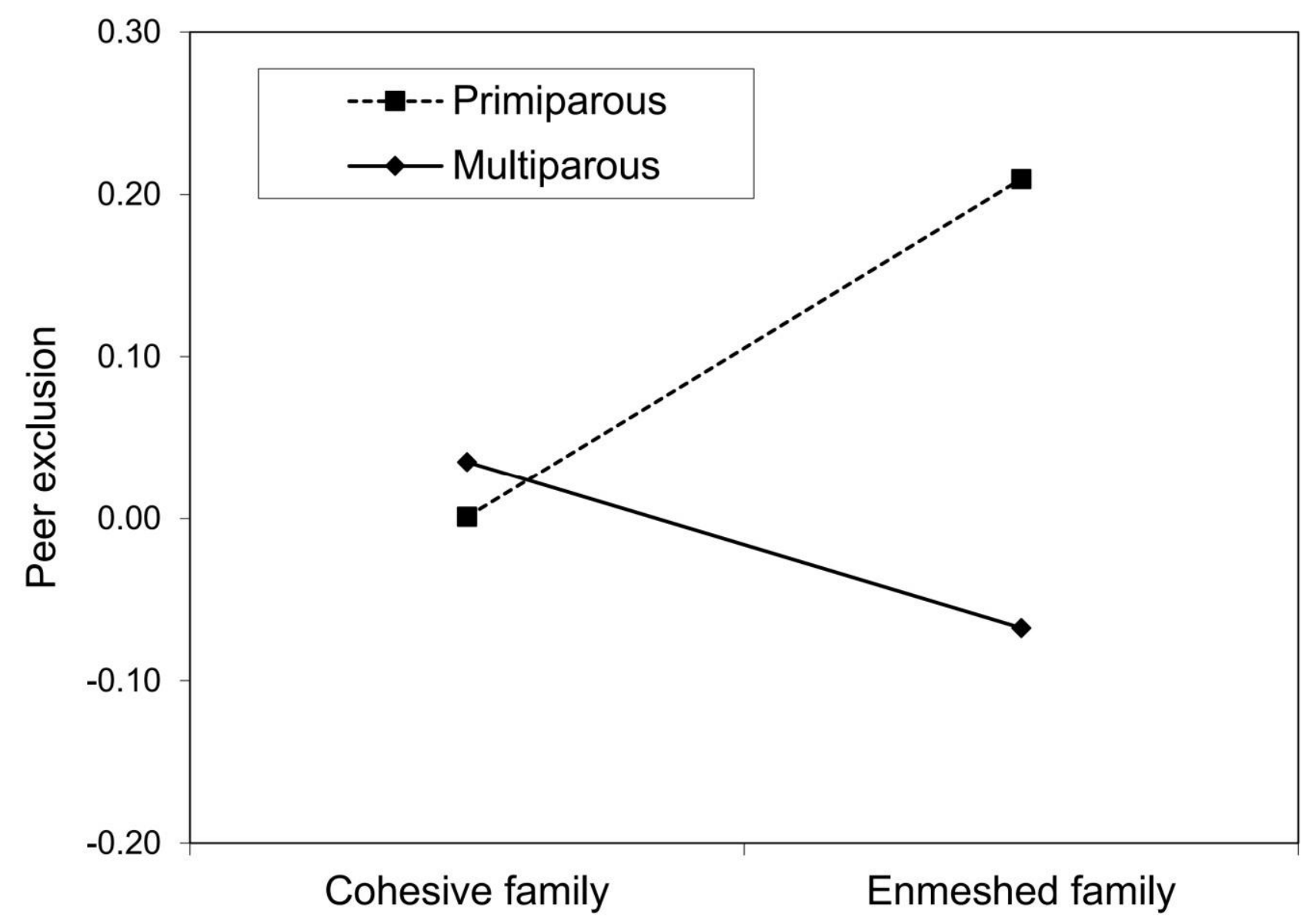

Note. Among primiparous parents enmeshed family predicted children's heightened peer exclusion, $\beta=0.31, S E=0.09, p=.001$, whereas among multiparous parents enmeshed family did not predict children's peer exclusion, $\beta=-0.14, S E=0.13, p=.264$. 
Figure 5. Parental Education level Moderates the Effects of Authoritarian (vs Cohesive) Families on Children's Emotion Regulation.

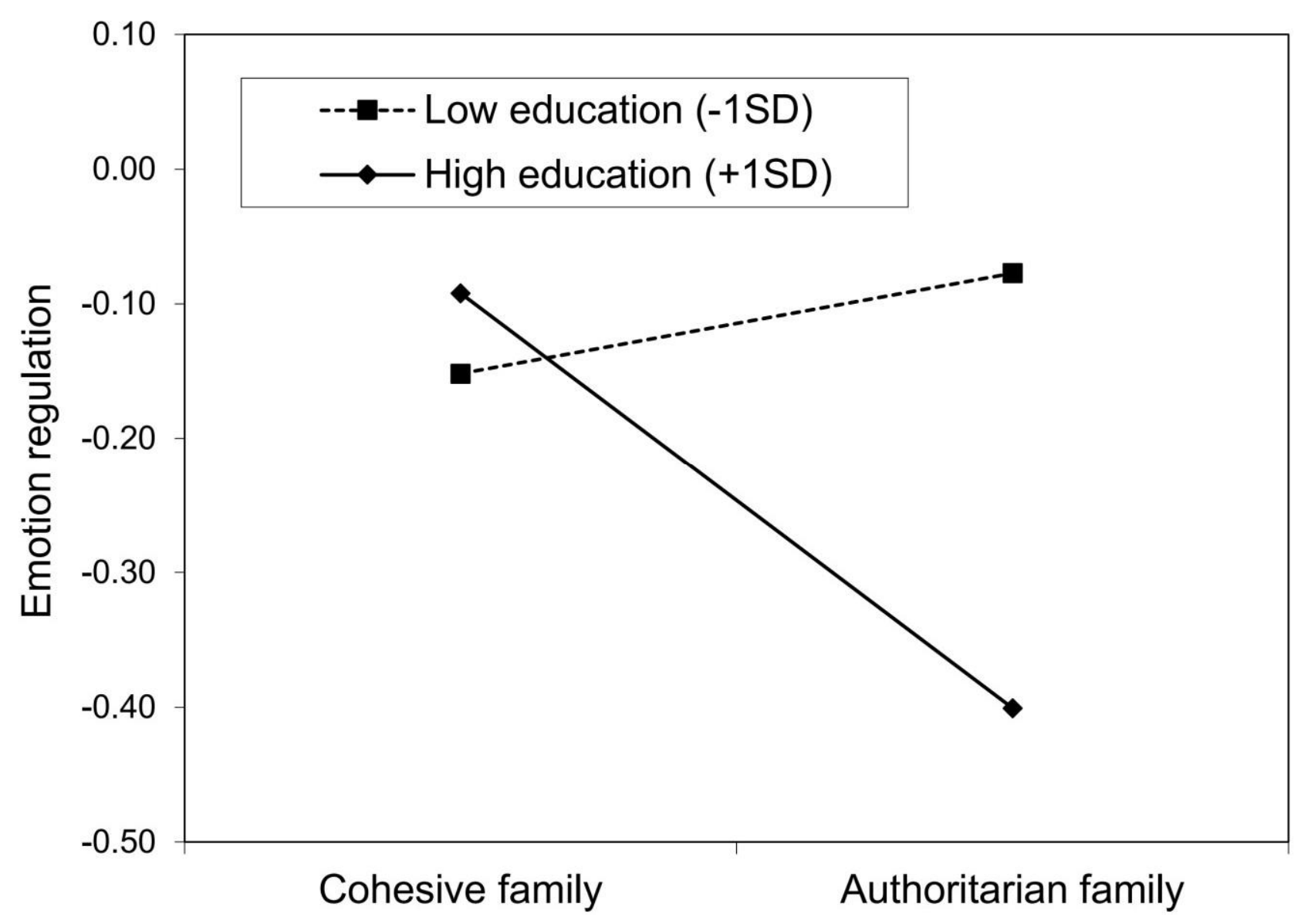

Note. In authoritarian families high parental education predicted inefficient emotion regulation, $\beta=-0.51, S E=0.23, p=.029$, whereas in cohesive families parental education did not predict emotion regulation, $\beta=0.05, S E=0.10, p=.599$. 
Figure 6. Mediation Model Depicting Pathways from Early Family System Types on Children's Anxiety and Depression at the Age of 7-8 Years.

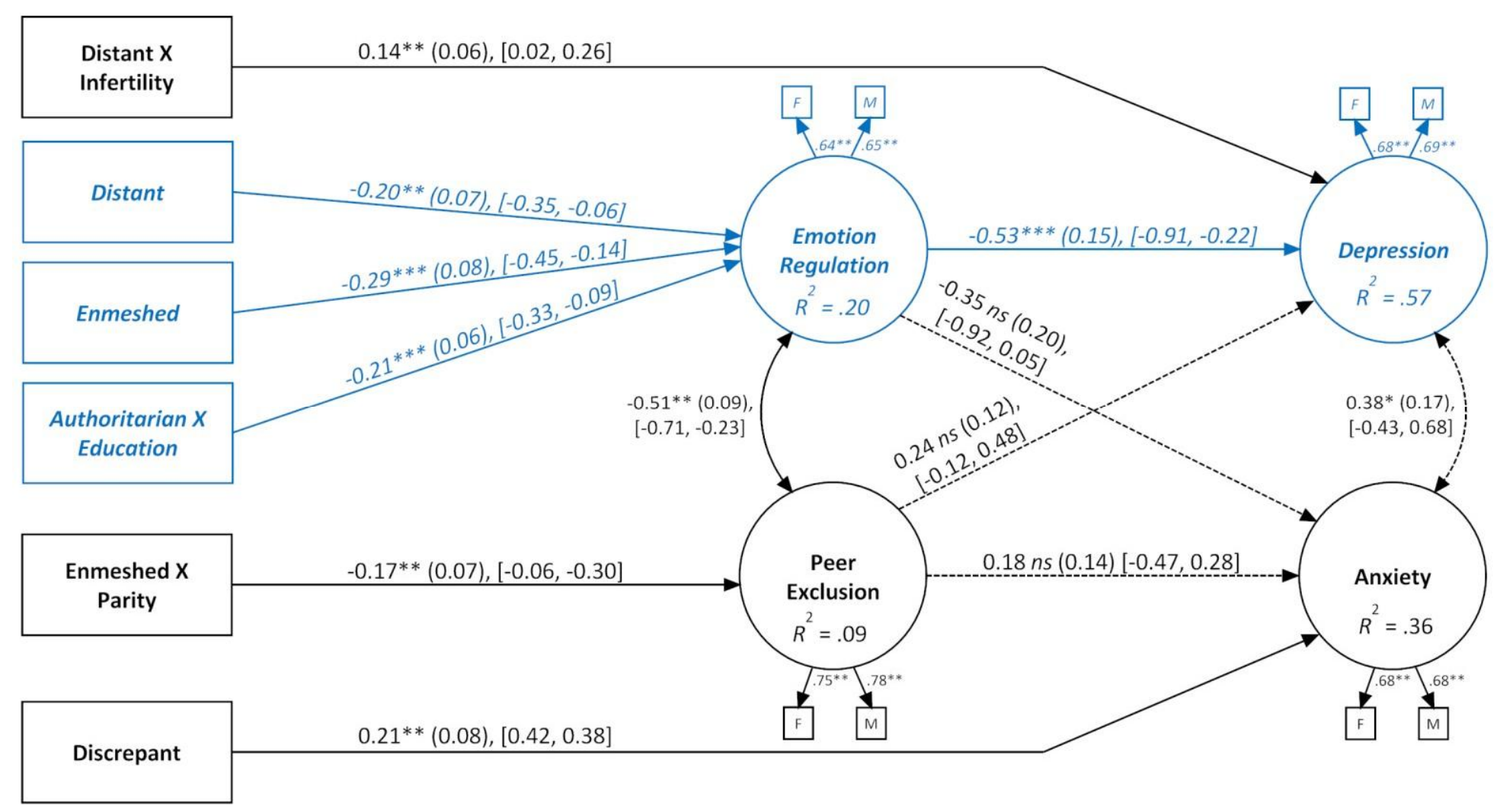

Note. Values refer to standardized beta coefficients, standard errors and 95\% confidence intervals, respectively. Blue color (text in italics) denote significant mediating pathway. Dashed lines denote nonsignificant paths. Letters $\mathrm{F}$ and $\mathrm{M}$ refer to fathers' and mothers' reports, respectively. Covariates and nonsignificant effects of family system types are not depicted. The model showed acceptable fit, $\chi^{2}(50)=44.59, p=.689$, CFI $=$ 1.000, TLI $=1.000$, RMSEA $<0.01 ; 90 \%$ CI $[0.00,0.03]$.

$* p<.05, * * p<.01, * * * p<.001$ 